\title{
Pencitraan 3D Data Geolistrik Resistivitas dengan RockworksBerdasarkan Hasil Inversi Res2DInv untuk Mengetahui Persebaran Batuan Konglomerat di Desa Surodadi, Kecamatan Gringsing, Kabupaten Batang
}

\author{
Taufik Nur Fitrianto*, Supriyadi dan Teguh Maulana Mukromin \\ Program Studi Fisika, Fakultas Matematika dan Ilmu Pengetahuan Alam, \\ Universitas Negeri Semarang, Semarang. \\ Jl. Raya Sekaran Gunungpati 50229 Semarang, JawaTengah \\ "Email: taufiknurfitrianto@gmail.com
}

\section{ABSTRACT}

Research was conducted to determine distribution of Conglomerate in Surodadi Village, Gringsing, Batang. The data acquisition used Schlumberger array. The length of line is $165 \mathrm{~m}$ and $15 \mathrm{~m}$ electrode spacing. The data processing used Microsoft Excel and 2D imaging used Res2Dinv. Then 3D imaging used Rockworks from result of Res2DInv inversion. The position data was used on UTM coordinate from position data each of electrode. The data acquisition was done at two parallel lines. In this area was found two types of rocks; tuffaceous sandstone and conglomerate. The conglomerate with resistivity values higher than $180 \Omega \mathrm{m}$ is distribution on southeast research area at the depth $5 \mathrm{~m}-25 \mathrm{~m}$. While the tuffaceous sandstone layers is distribution on northwest research area.

Keywords: Geoelectrical, Resistivity, Rock Layers, 3D Imaging, Conglomerate

\section{ABSTRAK}

Telah dilakukan penelitian untuk mengetahui sebaran batuan konglomerat di Desa Surodadi Kecamatan Gringsing Kabupaten Batang. Pengambilan data menggunakan metode geolistrik resistivitas dengan konfigurasi Schlumberger. Panjang lintasan penelitian adalah $165 \mathrm{~m}$ dengan jarak antar elektroda $15 \mathrm{~m}$. Data awal diolah menggunakan software Microsoft Excel dan pemodelan 2D menggunakan software Res2Dinv, kemudian melakukan pemodelan 3D menggunkan software Rockwork berdasarkan data resistivitas hasil inversi software Res2DInv. Data lokasi yang digunakan dalam pemodelan merupakan data dalam koordinat UTM berdasarkan data lokasi setiap elektroda. Pengambilan data dilakukan pada dua lintasan yang saling sejajar. Pada wilayah ini diperkirakan memiliki 2 jenis batuan yaitu batupasir tufan dan konglomerat. Batuan Konglomerat dengan nilai resistivitas lebih dari $180 \Omega \mathrm{m}$ tersebar merata di wilayah tenggara daerah penelitian pada kedalaman $5 \mathrm{~m}-25 \mathrm{~m}$. Sedangkan batupasir tufan tersebar merata di wilayah barat laut daerah penelitian.

Kata Kunci: Geolistrik, Resistivitas, Lapisan Batuan, Citra 3D, Batuan Konglomerat

\section{PENDAHULUAN}

Batuan Konglomerat adalah batuan sedimen dengan fragmen membundar berdiameter antara $2 \mathrm{~mm}-165 \mathrm{~mm}$. Batuan ini memiliki tingkat ekonomis yang tidak terlalu tinggi karena memiliki tingkat kekerasan yang rendah, sehingga tidak dapat dijadikan penyusunan utama bangunan. Namun dapat dijadikan bahan tambahan dalam bangunan dengan cara melepaskan ikatan antara fragmen. Batuan konglomerat juga dapat dijadikan hiasan untuk batuan penyusun yang memiliki warna mencolok. 
Metode geolistrik sering digunakan untuk penyelidikan air tanah, mencari lokasi patahan, eksplorasi mineral dalam tanah dan arkeologi ${ }^{[1]}$. Pendugaan geolistrik ini didasarkan pada kenyataan bahwa material yang berbeda akan mempunyai resistivitas yang berbeda apabila dialiri arus listrik. Salah satu metode geolistrik yang sering digunakan dalam pengukuran aliran listrik dan untuk mempelajari keadaan geologi bawah permukaan adalah metode resistivitas. Resistivitas merupakan salah satu sifat fisis yang dimiliki batuan, yaitu, kemampuan untuk dilewati arus listrik, jika batuan makin sukar dilewati oleh arus listrik maka semakin besar nilai resistivitas batuan tersebut ${ }^{[2]}$.

Pada metode geolistris, arus listrik diinjeksikan ke dalam bumi melalui dua elektroda arus, kemudian menukur beda potensial menggunakan dua elektroda ${ }^{[3]}$. Tujuan survey geolistrik resistivitas adalah untuk mengetahui resistivitas bawah permukaan bumi dengan melakukan pengukuran dipermukaan bumi ${ }^{[4]}$. Pendekatan yang paling sederhana dalam mempelajari aliran arus listrik di dalam bumi adalah bumi dianggap homogen isotropis ${ }^{[5]}$. Homogen isotropis merupakan anggapan bahwa bumi memiliki satu lapisan batuan dengan nilai resistivitas yang sama.

Konfigurasi Schlumberger seperti ditunjukkan dalam Gambar 1, mempunyai sensitivitas yang relatif sedang untuk struktur vertikal dan horizontal, sehingga penggunaan konfigurasi Schlumberger merupakan pilihan yang baik. Kedalaman pertengahan (median depth) konfigurasi Schlumberger kira-kira $10 \%$ lebih besar dari pada konfigurasi Wenner ${ }^{[6]}$.

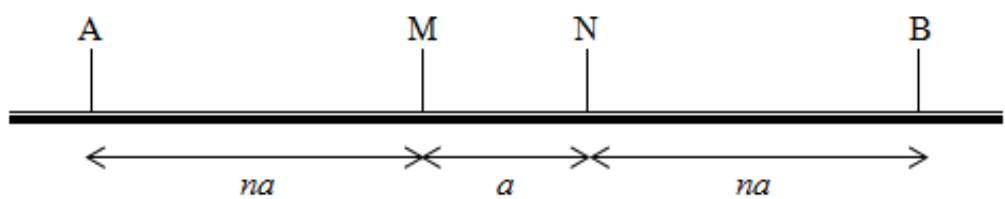

Gambar 1. Sketsa elektroda konfigurasi Schlumberger.

Resistivitas semu medium yang terukur dihitung berdasarkan persamaan

$$
\rho_{a}=K \frac{\Delta V}{I}
$$

dan faktor geometri pada konfigurasi Schlumberger

$$
K=\operatorname{\pi an}(n+1)
$$

Bumi diasumsikan sebagai bola padat yang mempunyai sifat homogen isotropis. Tetapi pada kenyataannya terdiri atas lapisan-lapisan dengan $\rho$ yang berbeda-beda sehingga potensial yang terukur merupakan pengaruh dari lapisan-lapisan disekitarnya. Maka harga resistivitas yang terukur bukan merupakan harga resistivitas untuk satu lapisan saja, tetapi beberapa lapisan.

Medium berlapis yang ditinjau terdiri dari dua lapis yang berbeda resistivitasnya ( $\rho_{1}$ dan $\rho_{2}$ ) dianggap sebagai medium satu lapis homogen yang memepunyai satu harga resistivitas, yaitu resistivitas semu $\rho_{a}($ Gambar 2). 


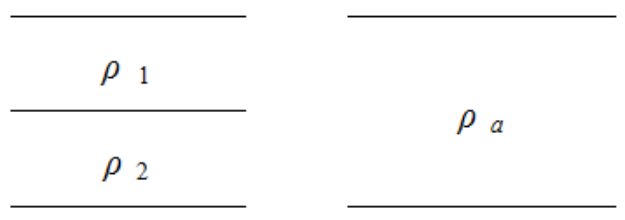

Gambar 2. Medium berlapis dengan variasi resistivitas

\section{METODE}

Pengambilan data dilakukan dengan cara pengukuran langsung menggunakan resistivitymeter jenis IPMGEO 4200 di Desa Surodadi, Kecamatan Gringsing, Kabupaten Batang. Pengambilan data dilaksanakan pada tanggal 19 Maret 2016.

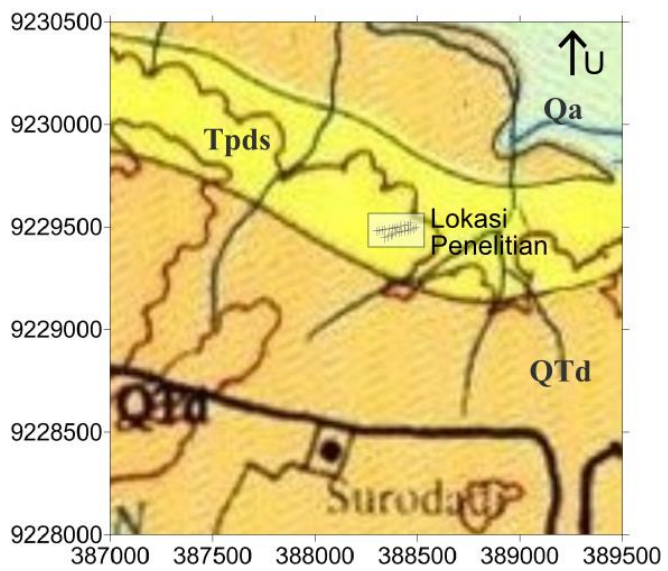

Gambar 3(Colour online). Titik lokasi pengambilan data

\section{Pengukuran Lapangan}

Pengukuran geolistrik menggunakan konfigurasi Schlumberger. Pengukuran dilakukan sebanyak 2 lintasan yang saling sejajar sepanjang $165 \mathrm{~m}$ (Gambar 3). Jarak antar elektroda terdekat yang digunakan adalah $15 \mathrm{~m}$. Posisi lintasan 1 berada di sebelah selatan lintasan 2. Pengambilan data dilakukan secara manual sesuai konfigurasi Schlumberger. Data yang diambil berupa data self potensial $(S P)$, kuat arus $\left(I_{\mathrm{AB}}\right)$ dan potensial $\left(V_{\mathrm{MN}}\right)$. Kemudian mengambil data posisi dan ketinggian dari setiap elektroda.

\section{Pengolahan Data}

Data yang didapat berupa $S P, I_{\mathrm{AB}}$ dan $V_{\mathrm{MN}}$. Kemudian data diolah menggunakan softwareMicrosoft Excel untuk mendapatkan nilai resistivitas semu. Dalam tahap pengolahan 2D menggunakan software Res2DInv. Selanjutnya menggunakan software Rockworks untuk pemodelan 3D.

\section{Interpretasi Data}

Dari penampang gambar geolistrik resistivitas dapat mengenali struktur bawah permukaan dengan mengamati kontras warna dari distribusi resistivitas bawah permukaan ${ }^{[7]}$. Namum batuan yang sama belum tentu mempunyai resistivitas yang sama, sebaliknya harga resistivitas yang sama bisa dimiliki oleh batuan-batuan yang berbeda, hal ini terjadi karena nilai resistivitas batuan memiliki rentang nilai yang bisa saling tumpang tindih ${ }^{[8]}$. 
Dari citra warna dan perbedaan resistivitasnya, maka dapat dilakukan identifikasi ${ }^{[9]}$, yang kemudian dikombinasikan dengan pengetahuan dasar aspek-aspek lain seperti informasi geologi.

\section{HASIL DAN PEMBAHASAN}

Pengukuran lapangan dilakukan dikawasan perbukitan Desa Surodadi yang terdiri dari 2 titik pengukuran yang saling sejajar. Panjang lintasan adalah 165 meter dengan jarak antar elektroda 15 meter. Pemilihan lokasi dilakukan di batas litologi yang ditandai perbedaan kondisi permukaan. Penggunaan dua lintasan dilakukan untuk mempermudah dalam melakukan pemodelan 3D.

Dari ploting data lokasi penelitian, diketahui bahwa penelitian dilakukan diatas anggota batupasir formasi damar (Tpds). Anggota Batupasir Formasi Damar mengandung batupasir tufan dan konglomerat, sebagian terikat kalsit. Bagian bawah berupa konglomerat aneka bahan tersemen karbonat. Ke atas menjadi batupasir tufan dan konglomerat andesit, sebagian tersemen karbonat ${ }^{[10]}$.

\section{Lintasan 1}

Setelah melakukan pengolahan data menggunakan softwareMicrosoft Excel dan Res2DInv diperoleh penampang 2D lintasan 1 .

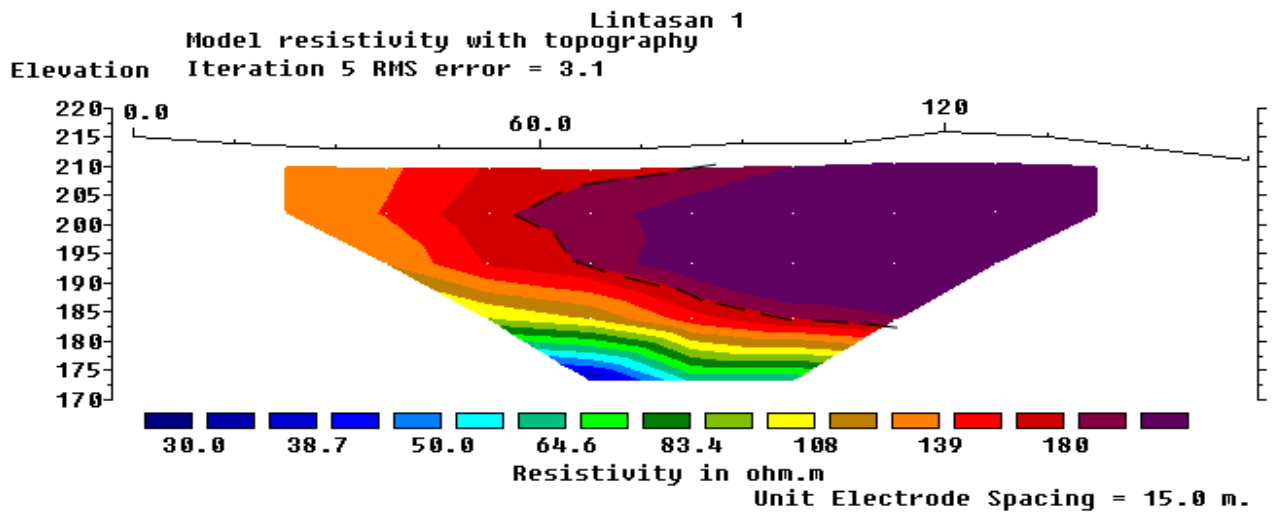

Gambar 4(Colour online). Penampang resistivitas lapisan bawah permukaan 2-D pada lintasan 1

Dari hasil pengolahan data seperti ditunjukkan dalam Gambar 4, lintasan 1 memiliki variasi nilai resistivitas pada rentang $33 \Omega \mathrm{m}-288 \Omega \mathrm{m}$. Dari data rentang nilai resistivitas dan jenis batuan berdasarkan kondisi geologi daerah penelitian. Diperkirakan pada lintasan ini memiliki 2 jenis batuan yaitu batupasir tufan dan konglomerat. Untuk data dengan nilai resistivitas $33 \Omega \mathrm{m}-139 \Omega \mathrm{m}$ diinterpretasikan sebagai batupasir tufan yang dicitrakan warna biru sampai warna jingga. Sedangkan untuk nilai resistivitas $180 \Omega \mathrm{m}-388 \Omega \mathrm{m}$ diinterpretasikan sebagai batuan konglomerat yang dicitrakan dengan warna ungu.

Dari citra penampang 2D lintasan 1 diketahui bahwa batuan konglomerat berada dikedalaman kurang dari 5 meter sampai $25 \mathrm{~m}$. Pada citra ini juga terlihat batuan konglomerat hanya ada pada meter ke 60 sampai meter ke 165 . Untuk jenis batuan konglomerat pada lokasi ini merupakan batuan konglomerat dengan fragmen andesit.

\section{Lintasan 2}

Setelah melakukan pengolahan data menggunakan softwareMicrosoft Excel dan Res2DInv diperoleh penampang 2D lintasan 2. 


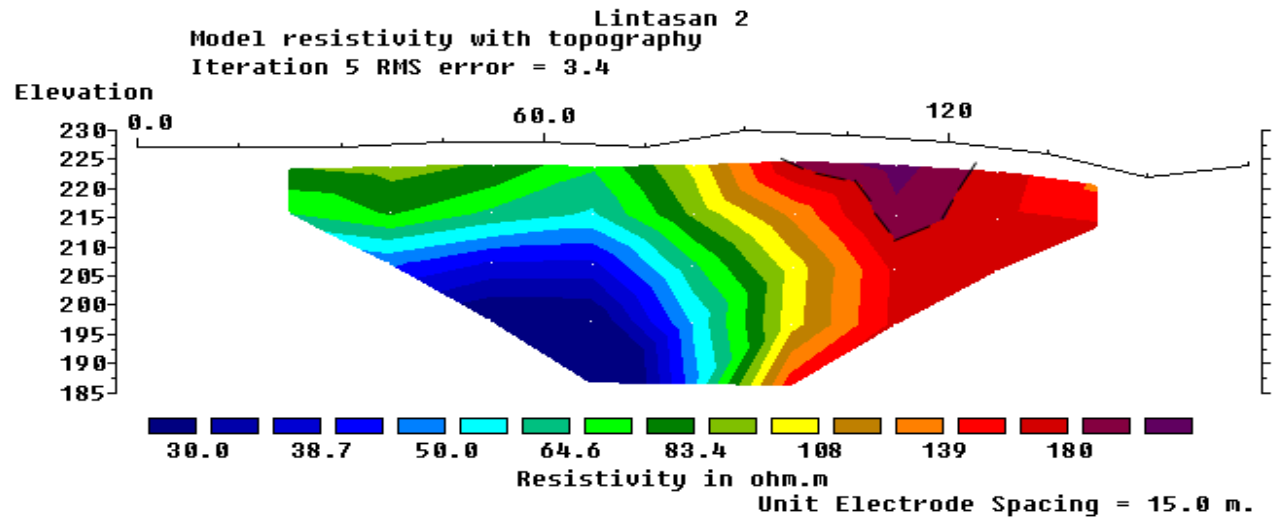

Gambar 5(Colour online). Penampang resistivitas lapisan bawah permukaan 2-D pada lintasan 2

Dari hasil pengolahan data pada Gambar 5, lintasan 2 memiliki variasi nilai resistivitas pada rentang $17 \Omega \mathrm{m}-217 \Omega \mathrm{m}$. Dari data rentang nilai resistivitas dan jenis batuan berdasarkan kondisi geologi daerah penelitian. Diperkirakan pada lintasan ini memiliki 2 jenis batuan yaitu batupasir tufan dan konglomerat. Untuk data dengan nilai resistivitas 17 $\Omega m-139 \Omega \mathrm{m}$ diinterpretasikan sebagai batupasir tufan yang dicitrakan warna biru sampai warna jingga. Sedangkan untuk nilai resistivitas $180 \Omega \mathrm{m}-217 \Omega \mathrm{m}$ diinterpretasikan sebagai batuan konglomerat yang dicitrakan dengan warna ungu.

Dari citra penampang 2D lintasan 2 diketahui bahwa batuan konglomerat berada dikedalaman kurang dari 5 meter sampai $10 \mathrm{~m}$. Pada citra ini juga terlihat batuan konglomerat hanya ada pada meter ke 90 sampai meter ke 125 . Untuk jenis batuan konglomerat pada lokasi ini merupakan batuan konglomerat dengan fragmen andesit. Pada lokasi ini hanya sedikit ditemukan jenis batuan konglomerat yang dapat dilihat dari sedikitnya citra warna ungu.

\section{Pemodelan 3D}

Sebelum melakukan pemodelan 3D, data lokasi lintasan 1 dan lintasan 2 diploting sehingga bisa mengetahui persebaran data yang akan dimodelkan (Gambar 6).

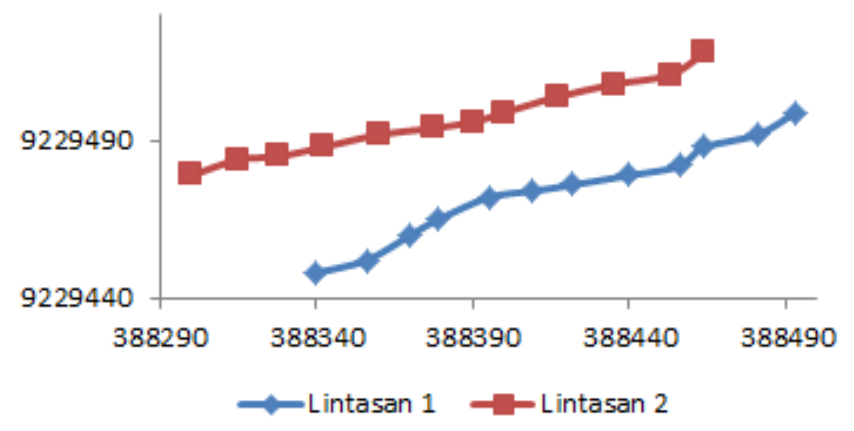

Gambar 6(Colour online). Lokasi Lintasan 1 dan Lintasan 2

Pada pemodelan 3D data posisi titik yang digunakan adalah data lokasi dalam UTM sesuai dengan data lokasi setiap elektroda. Untuk data nilai resistivitas yang digunakan adalah data nilai resistivitas hasil inversi dari software Res2DInv. Setelah melakukan pengolahan data menggunakan software Rockworks diperoleh citra 3D. 


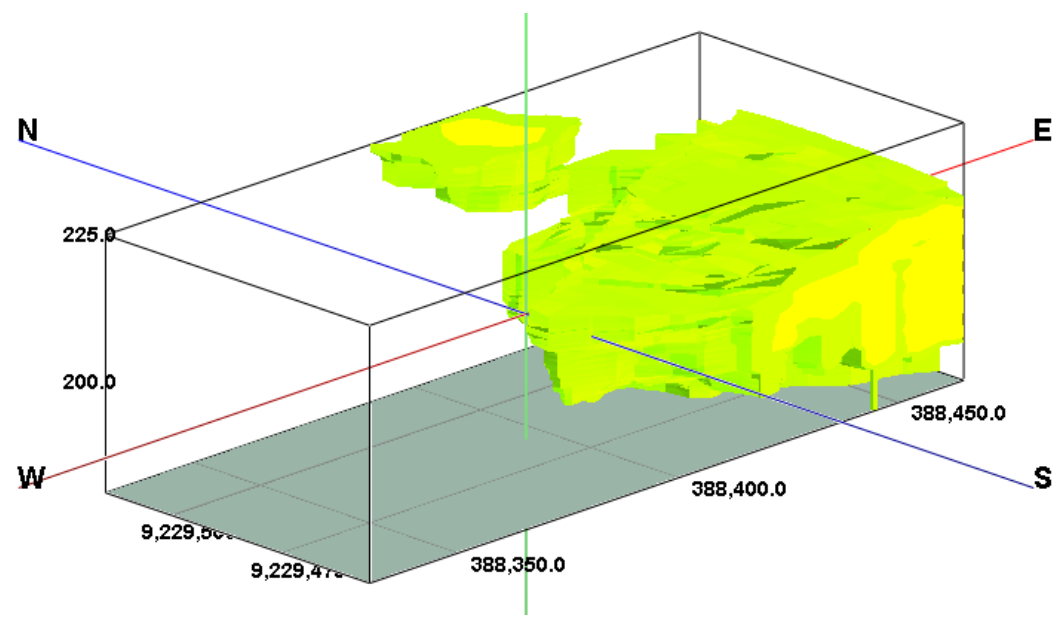

Gambar 7(Colour online). Citra 3-D Sebaran Batuan Konglomerat

Dari citra 3D terlihat persebaran batuan konglomerat tersebar merata di wilayah tenggara daerah penelitian. Dengan koordinat $388400 \mathrm{mT}-3884600 \mathrm{mT}$ dan seterusnya ke arah timur dan koordinat $9229500 \mathrm{mU}$ - $9229400 \mathrm{mU}$ dan seterusnya ke arah selatan. Batuan Konglomerat berada pada ketinggian 190 mdpl sampai 225 mdpl. Sedangkan untuk wilayah utara dan barat cenderung berkurang bahkan tidak ditemukan batuan konglomerat. Pada wilayah barat laut lebih banyak ditemukan batuan berupa batupasir tufan (Gambar 7).

\section{KESIMPULAN}

Pada wilayah ini diperkirakan memiliki 2 jenis batuan yaitu batupasir tufan dan konglomerat. Batuan Konglomerat dengan nilai resistivitas lebih dari $180 \Omega \mathrm{m}$ tersebar merata di wilayah tenggara daerah penelitian dengan kedalaman $5 \mathrm{~m}-25 \mathrm{~m}$. Sedangkan batupasir tufan tersebar merata di wilayah barat laut daerah penelitian.

\section{DAFTAR PUSTAKA}

1 Reynold, J.M. 1997. An Introduction to Apllied and Environtmental Geophysics. New York: Jhon Wiley \& Sons, Ltd.

2 Suyanto, I., \& Utomo, A. S. 2014. Analisis Data Resistivitas Dipole-dipole Untuk Identifikasi Dan Perhitungan Sumber Daya Asbuton Di Daerah Kabungka, Pasarwajo, Pulau Buton, Sulawesi Tenggara. Jurnal Fisika Indonesia, 17 (50), 1-7.

3 Supriyadi, Khumaedi, \&A.S.P. Putro. 2017. Geophysical and Hydrochemical Approach forSeawater Intrusion in North Semarang, Central Java,Indonesia.International Journal of GEOMATE: geotechnique, construction material and environment, 12, 133-139.

4 Damayanti, T, Supriyadi \&Khumaedi. 2011. Aplikasi Metode Geolistrik Skala Model Untuk Menentukan Nilai Resistivitas Lapisan Tanah Yang Mengalami Pencemaran. Jurnal Pendidikan Fisika Indonesia (Indonesian Journal of Physics Education), 7 (2), 138-144.

5 Telford, W.M., L.P. Geldart, R.E. Sheriff, \& D.A. Keys. 1990. Applied Geophysic. Cambridge: Cambridge University.

6 Loke, M. H. 1999. Electrical imaging surveys for environmental and engineering studies. A practical guide to 2-D and 3-D surveys

7 Neyamadpour, A., Abdullah, W. W., \& Taib, S. 2010. Use of four-electrode arrays in three-dimensional electrical resistivity imaging survey. Studia Geophysica et Geodaetica, 54, (2), 299-311. 
8 Siregar, J. 2006. Pendugaan Geolistrik Resistivitas Sounding Dalam Penyelidikan Akuifer Air Tanah di Kabupaten Sragen. Skripsi. UMS Surakarta.

9 Putri, F., Yulianto, A., \& Supriyadi. 2013. Monitoring Rembesan Embung Universitas Negeri Semarang dengan Metode Resistivity. Unnes Physics Journal, 2 (2), 13-17.

10 Condon W. H., Paryanto, Ketner K. B., Amin T. C., Gafoer S. \& Samodra. 1996. Peta Geologi Lembar Banjarnegara dan Pekalongan, Jawa, skala 1:100.000. Bandung: Puslitbang Geologi 